\title{
Metadiscourse in upper secondary pupil essays: Adapting a taxonomy
}

\author{
James Jacob Thomson \\ University of Stavanger
}

\begin{abstract}
The concept of metadiscourse, which refers to a range of interactional and organisational linguistic resources, has been increasingly used in studies that analyse professional and tertiary-level writing. Although studies tend to support the teaching of metadiscourse to tertiary-level students and have even promoted its potential value at the pre-tertiary level, the pool of studies that have investigated upper secondary pupil writing is relatively small. This study contributes to this research pool by investigating metadiscourse in 56 English essays belonging to five genres written at Norwegian and British upper secondary schools. By adapting a taxonomy based on several previous studies, the analysis accounts for the particular metadiscourse features in the corpus, and identifies which features characterise each of the five genres. For example, linguistic investigations, which were longer and more academic-like, used more topic and phoric markers to guide readers through the essay's content. Opinion pieces, in contrast, contained more engagement markers and boosters as pupils were tasked with targeting a lay audience. The results have implications for future research that aims to investigate the use of metadiscourse in pre-tertiary writing.
\end{abstract}

Keywords: Signposting; stance; novice writing

Responsible editor: Per Henning Uppstad

Received: June, 2019; Accepted: November, 2019; Published: February, 2020

\section{Introduction}

Over the past few decades, metadiscourse, a term that refers to linguistic resources that have interactional and organisational functions, has been the focal point of a growing number of studies investigating the interpersonal features of professional writing (e.g. Cao \& Hu, 2014; Fu \& Hyland, 2014). Although Hyland (2017) has documented the growing range of research directions in which metadiscourse is being taken, such as academic speaking and online-communication, Ädel (2018, p. 55) maintains that it is predominantly "highly visible and high-prestige genres in academia that have been investigated thus far". Although pre-tertiary writing is not far removed from such high-prestige genres, it has received little attention in previous

^Correspondence to: James Jacob Thomson, email: james.thomson@uis.no

(C) 2020 James Jacob Thomson. This is an Open Access article distributed under the terms of the Creative Commons Attribution 4.0 International License (https://creativecommons.org/licenses/by-nc/4.0/), allowing third parties to copy and redistribute the material in any medium or format and to remix, transform, and build upon the material for any purpose, even commercially, provided the original work is properly cited and states its license.

Citation: F. F. Thomson. "Metadiscourse in upper secondary pupil essays: Adapting a taxonomy" Nordic fournal of Literacy Research,Vol. 6(1), 2020, pp. 26-48. http://dx.doi.org/10.23865/njlr.v6.1720 
studies (e.g. Dobbs, 2013). This study therefore aims to contribute to the relatively small body of research by analysing English essays written by upper secondary pupils based at Norwegian and British schools. The aim of this study is not to compare how first and second language speakers of English use metadiscourse, but instead to investigate metadiscourse in essays written in the British and Scandinavian contexts, in which pupils in the latter are expected to be of B2-proficiency or higher (Council of Europe 2001). Norway is ranked third of 100 countries in terms of English skills (Education First, 2019), indicating that upper secondary pupils studying English should be highly proficient. Norwegian and British classrooms today often comprise pupils with various linguistic backgrounds so, rather than comparing groups based on their first languages, this study addresses the impact that educational systems have on pupils' literacy skills. It is these educational systems that determine the genres in which pupils write, which may consequently influence teacher advice regarding, for example, metadiscourse features. By combining categories from several previous studies (e.g. Hyland, 2019; Ädel, 2006) and using search terms based on the present corpus (Qin \& Uccelli, 2019), this study addresses the following research questions:

1. Which metadiscourse features are present in five genres of non-fiction English essays written by upper secondary pupils attending Norwegian and British schools?

2. How are metadiscourse features used in each of the five genres in the corpus?

This study proposes a taxonomy suited to analysing upper secondary level writing and exemplifies how pupils make use of each of the categories in five genres. Since the models used in the majority of previous studies were based on features of professional writing (e.g. Hyland, 2019), they may not account for all the features of upper secondary pupil writing (e.g. Qin \& Uccelli, 2019). While professional writing often serves to communicate with a wider audience, school-based writing is often aimed at teachers and examiners who are testing pupils' subject-based knowledge and writing skills. In order to account for this, a taxonomy was devised based on the content of the current corpus. The corpus consists of essays written for assessments set by teachers at four schools based on exam board criteria (e.g. AQA, 2019), thus providing a basis for investigating the metadiscoursal resources on which upper secondary pupils rely.

\section{Metadiscourse-related research}

Previous studies have offered various operationalisations of metadiscourse, such as Ädel's (2006) reflexive model, and Abdi, Rizi and Tavakoli's (2010) cooperative model. One of the most widely used is the interpersonal model (e.g. Vande Kopple, 1985), which is based on Halliday and Matthiessen's (2014) three metafunctions of language: ideational, interpersonal and textual. Ideational aspects of language embody the main message that one wishes to express. Interpersonal aspects function 


\section{F. F. Thomson}

to maintain social relationships. Textual aspects function to organise the unfolding discourse. Linguistic aspects that function either interpersonally or textually are considered to be metadiscourse, which can be defined as "aspects of a text which explicitly organize a discourse or writer's stance towards either its content or the reader" (Hyland, 2019, p. 16). While previous studies refer to interpersonal aspects as interactional metadiscourse (e.g. Hu \& Cao, 2015), this study uses the term 'stance' (Hyland, 2005), and while previous studies refer to textual aspects as interactive metadiscourse (e.g. Cao \& Hu, 2014), this study uses the term 'signposting' (Abdi \& Ahmadi, 2015). Additionally, like Ifantidou (2005), this study rejects the idea that metadiscourse should be considered to be non-propositional (e.g. Vande Kopple, 1985), instead recognising that, considering their semantic and pragmatic value, signposting and stance markers contribute to propositional content.

A large body of research has investigated metadiscourse in English writing in professional and tertiary-level contexts. These studies have had a variety of foci, such as identifying genre features (e.g. Hempel \& Degand, 2008) or comparing metadiscourse across languages (e.g. Dahl, 2004). A wide range of professional genres have been analysed, including academic writing ( $\mathrm{Hu} \& \mathrm{Cao}, 2015)$, newspaper discourse (e.g. Dafouz-Milne, 2008; Khabbazi-Oskouei, 2013), and popular science articles (Fu \& Hyland, 2014). These studies have highlighted both the functions that signposts and stance markers fulfil and the ways in which these features typify each genre. For example, Fu and Hyland (2014) found that authors of popular science articles persuade their audience by hedging scientific claims while avoiding questions and first person pronouns, thus allowing scientific findings to speak for themselves. Authors of opinion pieces, on the other hand, address their audience directly, ask questions, and boost claims to persuade their readers (Fu \& Hyland, 2014, p. 24-25).

Unlike previous studies, the present study does not compare how first and second language speakers of English use metadiscourse, focusing instead on educational contexts, but studies that have compared metadiscourse across various language contexts are considered relevant, nevertheless (e.g. Crismore, Markkanen \& Steffensen, 1993). A handful of studies have compared the use of metadiscourse in Scandinavian languages with English (e.g. Blagojevic, 2004; Dahl, 2004). Findings have shown that Norwegian academic authors use metadiscourse at similar frequencies to British authors, both when writing in their mother tongue and when writing in English (Blagojevic, 2004; Dahl, 2004). This indicates that rhetorical practices in professional Norwegian and English writing are similar compared with other languages, such as French, where authors have been found to use around half the number of signposts (Dahl, 2004).

Metadiscourse in tertiary-level English writing has received considerable attention (e.g. Çandarli, Bayyurt \& Mart1, 2015; Hasselgård, 2016; Ho \& Li, 2018; Qin \& Uccelli, 2019; Ädel, 2006). Hasselgård (2016) compared professional and novice writing, finding that professional writing contains lower frequencies of signposting. Hasselgård (2016, p. 127) argued that professional writing is more reader-responsible, 
meaning that it relies on fewer signposts as readers are expected to navigate their own way through the text (Hinds, 2011). In Scandinavian-based studies of tertiary-level writing, students who speak English as an additional language were found to use more metadiscourse than native speakers (Hasselgård, 2016; Ädel, 2006). Ädel (2006, p. 154) offered several explanations for these findings, such as that the students had different cultural backgrounds, or that they were writing for different purposes.

Only a handful of studies have analysed metadiscourse-related features in essays written at pre-tertiary levels (e.g. Dobbs, 2014). Qin and Uccelli (2019) compared metadiscourse used by high school, undergraduate and graduate students, finding, for example, that the youngest group used fewer hedges. Uccelli, Dobbs and Scott (2013) investigated how textual quality correlates with metadiscoursal features in upper secondary persuasive essays. They found that higher frequencies of signposts and hedges significantly correlated with higher quality, alluding to the teachers' values, such as good organisation and acknowledging other perspectives. Since pedagogical courses often focus on training teachers to write academically, they argued, "it is not surprising that the features they would value in their students' writing are in fact core markers of organisation and stance in skilled academic writing" (Uccelli, Dobbs \& Scott, 2013, p. 53). Finally, none of the reviewed studies analyse metadiscourse in pre-tertiary English writing in a Scandinavian context.

\section{Methods}

For this exploratory study, a corpus of upper secondary pupil essays was collected and analysed using an adapted taxonomy. Based on the results of descriptive statistical testing (Lowie \& Seton, 2013), this study presents the metadiscourse features of pupils' writing in each genre and in the corpus overall. This section explains the procedure for compiling the corpus and outlines how categories were chosen for the taxonomy.

\section{Building the corpus}

For the purposes of this exploratory study, a small corpus of essays was collected from two Norwegian schools and two British schools (see Table 1).

The sample was a convenience sample since the schools were contacted via this study's affiliated university. The British and Norwegian educational systems group pupils by age differently ${ }^{1}$, so data was collected from pupils completing their final school year, as these pupils may be preparing to begin tertiary studies, meaning that this study may be relevant for both school and university teachers. Altogether, the corpus comprises 56 essays, 35 written by 30 pupils at the British schools $(72,442$ words) and 21 written by five pupils at the Norwegian schools (25,001 words).

\footnotetext{
${ }^{1}$ At Norwegian and British schools, pupils complete their final school year between the age of $17-18$ and $18-19$, respectively.
} 
Table 1. Text types in corpus written at British and Norwegian schools.

\begin{tabular}{|c|c|c|c|c|}
\hline & \multicolumn{2}{|c|}{$\begin{array}{c}\text { Total number of texts } \\
\text { (number of pupils) }\end{array}$} & \multirow[t]{2}{*}{$\begin{array}{l}\text { Total word count } \\
\text { and average length }\end{array}$} & \multirow{2}{*}{$\begin{array}{c}\text { Average } \\
\text { grade and } \\
\text { range }\end{array}$} \\
\hline & UK & Norway & & \\
\hline Political analyses (timed) & - & $10(2)$ & $11,182(1118)$ & $\mathrm{C}(\mathrm{B}-\mathrm{E})$ \\
\hline Literary analyses (timed) & - & $11(3)$ & $13,819(1256)$ & $\mathrm{C}(\mathrm{B}-\mathrm{E})$ \\
\hline Linguistic investigations (coursework) & $81(8)$ & - & $21,918(2740)$ & $\mathrm{A}(\mathrm{A}-\mathrm{B})$ \\
\hline Opinion pieces (coursework) & $5]^{(8}$ & - & $5,212(1042)$ & $\mathrm{B}(\mathrm{A}-\mathrm{C})$ \\
\hline Reflective pieces (coursework) & $22(22)$ & - & $45,312(2060)$ & B (A-F) \\
\hline Total & $35(30)$ & $21(5)$ & 97,470 & \\
\hline
\end{tabular}

Although the corpus is too small for performing inductive statistical tests, it provided rich data for exploring the kinds of metadiscourse that pupils at this level rely on. While most of the pupils were native speakers of English or Norwegian, five pupils reported having other first languages. Nevertheless, these pupils were considered proficient enough to participate in mainstream English classes. Prior to the final year of upper secondary school, pupils in Norway receive 968 hours of English tuition, and it seems that the pupils involved in this study were at least at the C1 proficiency level, meeting the Council of Europe's criterion: "Can write clear, well-structured expositions of complex subjects, underlining the relevant salient issues" (2001, p. 62). However, this study does not aim to compare metadiscourse in essays written by first and second language speakers, focusing instead on identifying metadiscoursal features in five genres written in the Norwegian and British contexts.

The collected essays were written as part of evaluations set by teachers and based on criteria outlined by exam boards (AQA, 2019; Udir, 2013) for English subjects, which was considered preferable to administering a single pre-fabricated task. The essays written at Norwegian schools were written under timed conditions, while those at the British schools were written as coursework. Since the schools were responsible for implementing these evaluations, they represent the conditions under which pupils may usually work (Mackey \& Gass, 2016).

The texts in the corpus were grouped into five genres based on their topic and function (Paltridge, 1995): political analyses, literary analyses, linguistic investigations, opinion pieces and reflective pieces. The political analyses aimed to discuss political issues. In the literary analyses pupils discussed their interpretations of various literary works. The linguistic investigations were reports of linguistic studies that the pupils had carried out. The opinion pieces aimed to engage a lay newspaper-reading audience in linguistic topics. The reflective pieces were about the processes and inspirations behind a series of creative pieces that pupils had written as coursework.

\section{A metadiscourse taxonomy}

In order to compile the taxonomy for this study, categories and search terms were adopted from previous studies (e.g. Hyland, 2019; Ädel, 2006) based on a close 
reading of around 30 of the texts in the corpus. The present study defines metadiscourse as linguistic resources that serve interactional and organisational functions (e.g. Hyland, 2019), corresponding to two main metadiscoursal functions: "signposting" (Table 2) and "stance" (Table 3).

Signposting refers to words and phrases that writers use to guide their readers through the unfolding text (Abdi \& Ahmadi, 2015). The signposting aspect has four main categories that are further divided into ten sub-categories. The transition and code gloss sub-categories have previously been used in studies that draw on Hyland's (2019) interpersonal model (Cao \& Hu, 2013). The phoric marker and topic marker categories have been used in studies that draw on Ädel's (2006) reflexive model (Hasselgård, 2016).

Table 2. Signposting categories (adapted from Hyland, 2005; 2007; 2019; Ädel, 2006; 2010; Cao \& $\mathrm{Hu}, 2014$; Hasselgård, 2016).

\begin{tabular}{lll}
\hline Category & Subcategories & Description and examples \\
\hline Transitions & Additive & Express relations of additions: as well, moreover \\
& Comparative & Express relations of comparison or contrast: or, in comparison \\
& Inferential & Express relations of cause and effect: in order to, therefore \\
Code glosses & Exemplification & Mark when an example is being given: illustrate, highlight \\
& Reformulation & Mark when a discourse unit is being reworded: in other words \\
Phoric markers & Enumerating & Make explicit how points in the text are organised: first, finally \\
& Pre- and reviewing & Refer to earlier or later parts of the text: I will, as mentioned \\
Topic markers & Introduction & Introduce the content of the text: this paper aims to \\
& Reference to text & Reflexively refer to the current text: essay, project \\
& Conclusion & Signal when conclusions are being drawn: overall \\
\hline
\end{tabular}

Stance refers to the words and phrases writers use in positioning themselves and their readers towards the material in question (Hyland, 2005). Based on Qin and Uccelli's (2019, p. 35) suggestion that studies should more finely distinguish metadiscoursal functions and based on previous studies that use sub-categories (e.g. Hinkel, 2005), this study offers an operationalisation of stance that splits six categories into 13 sub-categories. Hedges were recognised as either rounders, plausibility shields (Prince et al., 1980), downtoners (Hinkel, 2005) or first person hedges (Salager-Meyer, 1994). Boosters were recognised as either amplifiers, plausibility boosters or universals (Hinkel, 2005). Engagement markers (Hyland, 2005) include questions, reader references, directives and personal asides (Ädel, 2010). As with most previous studies, self-mentions and attitude markers were classed as stance markers (e.g. Qin \& Uccelli, 2019). Evidentials, which are often classed as signposts (e.g. Cao \& Hu, 2013), were not considered to have an organisational function in the present corpus. Instead, they were primarily considered to be persuasive, drawing readers' attention to external sources that support the writers' views and were therefore classified as stance markers following, for example, Dafouz-Milne (2008, p. 99). 


\section{F. F. Thomson}

Table 3. Stance categories (adapted from Dafouz-Milne, 2008; Hinkel, 2005; Hyland, 2005, 2019; Prince et al., 1980; Salager-Meyer, 1994; Ädel, 2010).

\begin{tabular}{|c|c|c|}
\hline Category & Subcategory & Description and examples \\
\hline \multirow[t]{4}{*}{ Hedges } & Downtoners & Scale down intensity: quite, relatively \\
\hline & Rounders & Mark when figures are inexact: roughly, around \\
\hline & Plausibility shields & Mark that a statement may not be true: potential, tend \\
\hline & First person hedges & Mark the author's involvement in a statement: my opinion, I guess \\
\hline \multirow[t]{3}{*}{ Boosters } & Amplifiers & Modify gradable adjectives or verbs and heighten their scalar \\
\hline & Universals & $\begin{array}{l}\text { lexical intensity: extremely, too, very } \\
\text { Mark the extremes of the continuum of meanings: all, everybody, } \\
\text { never }\end{array}$ \\
\hline & Plausibility boosters & $\begin{array}{l}\text { Mark that the author is certain of what they are writing: clear, } \\
\text { indeed, sure }\end{array}$ \\
\hline Engagement & Questions & Direct questions, tag questions, rhetorical questions \\
\hline \multirow[t]{3}{*}{ markers } & Reader reference & Address reader directly: $y o u$, we \\
\hline & Directives & Direct the reader to perform an action: look at, think about it \\
\hline & Personal asides & Mark non-integral information: by the way \\
\hline Evidentials & & $\begin{array}{l}\text { Mark that the author is referring to another source of information } \\
\text { describe, portray }\end{array}$ \\
\hline Self-mentions & & Explicitly mark author involvement in text: $I, m y$, we \\
\hline Attitude markers & & Express writer's attitude towards proposition: interesting, hopefully \\
\hline
\end{tabular}

In total, 526 items $^{2}$ (see appendix) were found to function metadiscoursally in the present corpus. This is a greater number of terms than has been found in a number of previous studies (e.g. Ho \& Li, 2018). This seems to result both from closely reading essays in the corpus and from recognising that metadiscourse carries propositional meaning (Ifantidou, 2005), meaning that a wider range of words and phrases can potentially fulfil the signposting and stance functions outlined above.

The reliability of the categories was tested in collaboration with a second rater, who was a graduate-level corpus linguist. The second rater and I analysed 10 of the 56 texts to test for inter-rater reliability, agreeing on 4325 out of 4735 instances $(>91 \%)$. The most problematic category was the enumerator category, scoring $76 \%$ after the discussion. This was largely due to instances of "finally" and "lastly", which were sometimes used to mark the ultimate point in a series and at other times used synonymously with "in conclusion" to mark the end of the text. The solution was to categorise latter instances as conclusion markers, recognising that the sentential context was insufficient and that the analysis needed to consider where these markers were situated in the entire text.

Attitude markers were challenging to work with. The search terms from Hyland (2019) were used for this study, as well as "honestly" and "significant". However, the

\footnotetext{
${ }^{2}$ The analysis initially used 587 search terms, but only the words and phrases that functioned metadiscoursally in this corpus are reported here.
} 
search terms did not account for a number of other words and phrases that pupils used to express their affective attitudes, such as "my favourite novel", "it became confusing" and "I like what I finished with". Such terms were not included as there seemed to be too many to conduct a manageable analysis. Attitude marker subcategories have been proposed, but these either mix formal and functional categories (e.g. Dafouz-Milne, 2008), or were considered to be too all-encompassing for this study (e.g. Martin \& White, 2005). Future research could aim to delimit the attitude marker category in order to apply it to non-academic genres.

To analyse the corpus, the 526 search terms were entered into the concordancing function in the program \#Lancsbox (Brezina, McEnery \& Wattam, 2015). The concordance lines were read manually to check whether each instance functioned metadiscoursally. For example, when "we" referred to a group to which the writer belonged, it was classed as a self-mention. When "we" included the reader, it was classed as a reader pronoun. When "we" appeared in a quote, it was excluded from the analysis. This study does not rely on inductive statistical tests, using instead descriptive statistics as a basis for identifying metadiscoursal features in each genre and in the corpus overall (Lowie \& Seton, 2013). The frequencies were calculated as the number of instances per 100 words. In the results, the text extracts are marked with the letters $\mathrm{N}$ and UK, representing Norwegian and British schools respectively. Pupils were assigned with a number and additional letters when they contributed with more than one essay. The search terms, which are either words, phrases or punctuation marks, are written in italics in the example extracts.

\section{Results}

This section presents the results from this exploratory analysis, using examples from the corpus to illustrate how each sub-category functioned in the five genres. The first sub-section presents the signposting results and the second sub-section presents the stance results.

\section{Signposting results}

In the corpus, there were 7018 signposting markers, with a mean of 6.62 per 100 words. The majority of the signposting categories were present in all five genres (see Table 4). The linguistic investigations contained the highest frequency of signposts overall, which likely links to the length and purpose of these texts: these were the longest and most academic-like texts in the corpus and the only ones that were split into sub-sections (e.g. "introduction", "methodology").

Transitions were the most frequently used metadiscourse category. There were high frequencies of transitions of addition, comparison and inference, although a small pool of words accounted for these high frequencies (e.g. "and", "also", "as", "but", "or", "so"). All three types are exemplified in the following extracts: 


\section{F. F. Thomson}

Table 4. Frequencies of signposts in each genre per 100 words.

\begin{tabular}{lccccc}
\hline Signposting categories & $\begin{array}{c}\text { Political } \\
\text { analysis }\end{array}$ & $\begin{array}{c}\text { Literary } \\
\text { analysis }\end{array}$ & $\begin{array}{c}\text { Linguistic } \\
\text { investigation }\end{array}$ & $\begin{array}{c}\text { Opinion } \\
\text { pieces }\end{array}$ & $\begin{array}{c}\text { Reflective } \\
\text { piece }\end{array}$ \\
\hline Addition & 2.91 & 3.49 & 3.46 & 2.89 & 2.74 \\
Comparison & 1.69 & 2.04 & 1.41 & 1.91 & 1.49 \\
Inference & 1.39 & 0.7 & 1.39 & 1.22 & 1.26 \\
Total transitions & 5.96 & 6.24 & 6.27 & 6.03 & 5.49 \\
Exemplification & 0.31 & 0.18 & 0.61 & 0.59 & 0.41 \\
Reformulation & 0.07 & 0.01 & 0.04 & 0.27 & 0.07 \\
Total code glosses & 0.38 & 0.2 & 0.65 & 0.86 & 0.48 \\
Pre- and review & 0.08 & 0.07 & 0.14 & 0.07 & 0.06 \\
Enumerate & 0.02 & 0.01 & 0.05 & 0.07 & 0.05 \\
Total phoric markers & 0.1 & 0.08 & 0.19 & 0.14 & 0.11 \\
Introduce & 0.07 & 0.02 & 0.07 & 0 & 0 \\
Reference to text & 0 & 0 & 0.28 & 0 & 0.01 \\
Conclude & 0.01 & 0.02 & 0.07 & 0.02 & 0.01 \\
Total topic markers & 0.09 & 0.04 & 0.41 & 0.02 & 0.02 \\
Total Signposts & 6.52 & 6.55 & 7.52 & 7.05 & 6.09 \\
\hline
\end{tabular}

1. This is because of his inventiveness and practicality. He can think rationally [...] and he is religious as well, but not fanatically. (N5, literary analysis)

2. This declarative is very off-topic but also rebellious because it suggests she is refusing to style-shift according to the formality of the situation (UK3, linguistic investigation)

Regarding code glosses, exemplifiers were quite frequent in all genres. The pupils often relied on examples to specify their intended meaning, to prove their understanding of terminology or to support their argumentation:

3. The factories used cheap energy like steam and coal to fuel the machines for production (N2b, political analysis)

4. There is also a use of alliteration, such as "venal vengeance" and "mischievous malice (N4b, literary analysis)

5. When men are referred to as animals it is often a positive thing. For example, we hear the term 'silver fox' (UK1b, opinion piece)

Reformulators, on the other hand, were infrequent in most genres, implying that the pupils rarely recognised a need for rewordings, perhaps because they expected their teachers to be familiar with terminology. The authors of the opinion pieces, however, often used reformulators to explain technical terms. Since their task was to write for everyday newspaper readers, the pupils seemed to use reformulators both to impress teachers with linguistic terminology and to engage their target lay audience:

6. Theorists of this kind ('sociolinguists') ${ }^{3}$ call this 'member resources' which basically means everything that makes up the world of this 'ideal consumer'. (UK5, opinion piece)

\footnotetext{
${ }^{3}$ Note that the search terms in extracts $6,35,36,38,41$ include brackets and question marks.
} 
Phoric markers were generally infrequent in the corpus with 19 essays containing no pre- and review markers and 38 essays containing no enumerators. Regarding pre- and review markers in these relatively short essays, the pupils may not have recognised a need to refer readers to other parts of the text. The linguistic investigations were the longest texts and thus had the highest frequencies of pre- and review markers. Previews were mostly used in introduction sections to signal upcoming content, often using "will" to fulfil this function. Reviews were often realised using "mentioned" and "again", and were largely used to signal when arguments were repeated:

7. This means the investigation will be diachronic in scope (UK5a, linguistic investigation)

8. This again links to Kroll's stages of writing development (UK2a, linguistic investigation)

The majority of pupils chose not to use enumerators, perhaps because they did not recognise a need to do so. The pupils that did use enumerators rarely used more than two or three in total, but one pupil used nine enumerators, two of which are shown in extract 9:

9. I had numerous key problems with this first draft, the first of which was that it was a poor location. [...] The second issue [was that] both characters were unengaging and unsympathetic (UK24, reflective piece)

Topic markers were also relatively infrequent in the corpus, perhaps again due to the short length of the texts. Introductory markers were not used in the opinion pieces or the reflective pieces, but were used in all eight of the linguistic investigations, which were organised into sub-sections and had a more academic style. They were also used in seven of the ten political analyses:

10. Introduction For my investigation, I have chosen to write about the topic of problem pages (UK1a, linguistic investigation)

11. In this essay the slave trade and abolition will be discussed (N1a, political analysis)

Concluding markers were used in only 16 of the 56 texts. As with introductory markers, all of the eight linguistic investigations contained concluding markers (e.g. "conclusion", "one might conclude that", "overall"), indicating that both the acts of introducing and concluding were a necessity in these texts.

Only the linguistic investigations contained a noteworthy number of references to the text itself. Although a word such as "investigation" may not solely refer to the current text, such words were counted when the current text was one of the denoted entities. In this genre, references to the text were often used to delimit the topic (12), to explain limitations (13) and to reflect on experiences (14):

12. This investigation aims to discover what the salient features are of a film blurb (UK6a, linguistic investigation) 


\section{F. F. Thomson}

13. The limitations in this study were that I have used quite a small sample ... (UK2a, linguistic investigation)

14. I greatly enjoyed doing this study as I was able to get an in-depth look into how entertainers actually make people laugh. (UK7, linguistic investigation)

Overall, transitions and exemplifiers were prominent signposting features in the corpus. Other signposting categories were also fairly frequent in the academic-like linguistic investigations. Otherwise, the short length of the essays required little signposting.

\section{Stance Results}

The frequencies of stance markers are presented in Table 5. There were a total of 7437 stance markers in the corpus, with a mean of 7.18 markers per 100 words. Regarding hedges, the linguistic investigations contained the highest frequency overall. However, each hedging sub-category was used somewhat idiosyncratically in each genre. Rounders were the most frequent sub-category in total, but were most prominent in the political analyses. In these essays, pupils tended discuss national and international issues and thus drew on statistics and broad generalisations in constructing their arguments:

15. This means around 40 Americans are killed by guns every day. (N1e, political analysis)

Table 5. Mean number of each stance category in each genre per 100 words.

\begin{tabular}{lccccc}
\hline Stance categories & $\begin{array}{c}\text { Political } \\
\text { analysis }\end{array}$ & $\begin{array}{c}\text { Literary } \\
\text { analysis }\end{array}$ & $\begin{array}{c}\text { Linguistic } \\
\text { investigation }\end{array}$ & $\begin{array}{c}\text { Opinion } \\
\text { piece }\end{array}$ & $\begin{array}{c}\text { Reflective } \\
\text { piece }\end{array}$ \\
\hline Downtoner & 0.13 & 0.27 & 0.3 & 0.36 & 0.42 \\
Rounder & 1.45 & 0.86 & 1.34 & 1.26 & 0.92 \\
Plausibility shields & 0.78 & 0.6 & 1.07 & 0.92 & 0.39 \\
First person hedge & 0 & 0.04 & 0.03 & 0 & 0.17 \\
Total hedges & 2.36 & 1.77 & 2.73 & 2.53 & 1.9 \\
Amplifier & 0.6 & 0.86 & 0.48 & 1.11 & 0.64 \\
Universal & 0.63 & 0.69 & 0.49 & 0.7 & 0.7 \\
Plausibility & 0.17 & 0.38 & 0.4 & 0.8 & 0.3 \\
Total boosters & 1.41 & 1.92 & 1.36 & 2.61 & 1.64 \\
Question & 0.04 & 0.16 & 0.01 & 0.49 & 0.01 \\
Reader reference & 0.17 & 0.39 & 0.08 & 2.02 & 0.25 \\
Aside & 0.02 & 0.01 & 0.01 & 0.11 & 0.08 \\
Directive & 0.02 & 0.02 & 0.02 & 0.12 & 0.01 \\
Total engagement markers & 0.2 & 0.57 & 0.12 & 2.74 & 0.35 \\
Evidentials & 0.69 & 0.87 & 1.01 & 0.79 & 0.22 \\
Self-mentions & 0 & 0.08 & 1.2 & 0.17 & 4.62 \\
Attitude markers & 0.22 & 0.05 & 0.19 & 0.37 & 0.19 \\
Total stance markers & 4.88 & 5.27 & 6.68 & 9.18 & 8.92 \\
\hline
\end{tabular}


16. For $s o m e^{4}$, this might sound more like a dictatorship, rather than democracy (N2a, political analysis)

In the opinion pieces, rounders again were often used to mark broad generalisations:

17. Frequently, parents cannot understand the technical language involved in many apps and technology. (UK2b, opinion piece)

In the linguistic investigations, pupils often relied on rounders when discussing the language features that they were analysing:

18. This colloquialism is often used in text messaging for brevity. (UK4a, linguistic investigation)

In general, downtoners were often used as a way of reducing the impact of statements. These hedges, along with first person hedges, were more frequent in the reflective pieces where pupils tentatively reflected on their creative writing decisions:

19. But on the other hand, the stories are also quite similar (N3c, literary analysis) 20. It's pretty clear how this line further complements the title (UK6b, opinion piece) 21. I believe I am quite strong at writing descriptively (UK25, reflective piece)

The pupils mostly used plausibility shields when tentatively making knowledge claims. These hedges were most frequent in the linguistic analyses, which were the most academic-like texts:

22. This could mean trouble for Trump's budget (N2d, political analysis)

23. Hamlet seems very depressed and confused as a person (N5a, literary analysis)

24. This interaction is likely to be a lot more effective (UK2b, opinion piece)

25. Kennedy appears to show a preference for the use of more abstract devices (UK8, linguistic investigation)

Plausibility shields were least frequent in the reflective pieces in which pupils were not required to make knowledge claims. When they were used in these pieces, plausibility shields were often used to recognise potential reader reactions to compositional choices:

26. It was best to ask other people as what I may remember as being hilarious may not be so funny to others. (UK17, reflective piece)

While hedges were almost twice as frequent as boosters in the political analyses and linguistic investigations, they were used at similar frequencies in the remaining genres. While the political analyses and the linguistic investigations were of an argumentative nature, the formal tone of these texts may have limited the extent to which pupils could assertively make claims without sourcing evidence. In opinion pieces,

\footnotetext{
${ }^{4}$ The word "some", referring here to "some people", is considered a rounder as it specifies that the author is not attributeing the statement to "all people".
} 


\section{F. F. Thomson}

on the other hand, pupils relied on a wider variety of rhetorical devices. The following extracts exemplify how boosters were used in opinion pieces in ways that would probably have been penalised in other genres:

27. Their world famous slogan 'Because you're worth it' really makes it sound as though it's you and only you that they are talking to. (UK5, opinion piece)

28. There exists a similar word for men, 'Satyriasis'. But, of course, no one has heard of this obscure word (UK1b, opinion piece)

In the linguistic investigations, plausibility boosters and universal boosters were sometimes paired with hedges, indicating that these pupils tried to find a more delicate balance between tentativeness and persuasion:

29. This implies that today's teenagers do not have $a n y^{5}$ sense of acceptable boundaries (UK3, linguistic investigation)

There were numerous boosters that arguably conveyed an inappropriate level of confidence. This inappropriateness is often related to the use of universal boosters, which were relatively frequent in all genres:

30. It is impossible to find the exact number of victims (N1b, political analysis)

31. Every human being consists of both good and evil (N4c, literary analysis)

32. These facts are always truthful and always back up what's said in the main advertisement (UK6b, opinion piece)

33. Everyone had more disposable income and they wanted cars (UK5a, linguistic investigation)

34. All bus journeys are they [sic] same which is something I'm sure we can all relate to. (UK28, reflective piece)

Engagement markers were more frequent in the opinion pieces, again highlighting how these pupils used a range of rhetorical devices in persuading their readers. The following extracts exemplify how the engagement marker sub-categories were used in the opinion pieces:

35. Who can really resist our favourite cheeky chappie, aye? (UK1b, opinion piece) 36. Another (yes, yet another) way that women are put down (UK1b, opinion piece) 37. Think about dove and their current success (UK5, opinion piece)

The corpus also provides evidence that the pupils adapted their metadiscoursal choices to the target genre. In the following extracts, one pupil liberally uses engagement markers and boosters in an opinion piece, whilst maintaining a more academic-like voice in their linguistic investigation:

\footnotetext{
${ }^{5}$ The word "any" is considered a booster here as it marks the extreme of teenagers not having acceptable boundaries, as opposed to "teenagers do not have $a$ sense of acceptable boundaries".
} 
38. Although all this really sounds like our favourite cheeky chap with his iconic bishbash-bosh cooking methods, who are we actually talking to? (UK4b, opinion piece)

39. Comparing texts from the $17^{\text {th }}$ century to the present day will hope to provide evidence of apparent change, including archaisms, semantic shifts and how modern day technology has influenced the English language (UK4a, linguistic investigation)

The literary analyses also contained noteworthy frequencies of questions and reader references. These pupils tended to write their essays as if they expected their readers to have read the literature in question:

40. We meet the Mr and Mrs Hurstwood who's got some issues in their relationship (N3a, literary analysis)

41. Is Hamlet right to describe himself as 'Essentially ... not in madness but in craft'? (N5, literary analysis)

Evidentials in the corpus were typically used either to cite extra-textual sources or to draw on the material that the pupils were analysing:

42. According to Gun Violence Archive [...], a total number of 12,392 American citizens have died by guns in 2016 in the USA. (N1e, Political analysis)

43. Brontë and Lawrence portray women's issues and rights in their story. (N3c, literary analysis)

44. Carr uses taboo lexis for comedic effect (UK7, linguistic investigation)

In the reflective pieces, however, evidentials were less frequent and, in a slightly different vein, functioned both to discuss other authors' compositional choices and to discuss compositional advice they received from teachers and friends:

45. Darren Shan also includes supernatural beings and themes (UK11, reflective piece)

46. My friends often tell me I am quite funny (UK17, reflective piece)

While self-mentions were almost entirely absent in the genres written at Norwegian schools (political analyses and literary analyses), these markers were frequent in the linguistic investigations and the reflective pieces. Despite the high frequencies of self-mentions in these genres, pupils infrequently made claims using first person hedges. In the linguistic investigations, pupils largely used self-mentions to reflect on the process of carrying out research. In the reflective pieces, the pupils used self-mentions to discuss their thought processes and decisions in writing their creative pieces:

47. I have learnt a great deal from my investigation (UK4a, linguistic investigation)

48. I think poetic form was an ideal choice to represent my style of creative writing. (UK9, reflective piece) 


\section{F. Thomson}

Of the attitude markers searched for, "interesting" and "important" were those that pupils most frequently resorted to using, but this category otherwise revealed little about the pupils' compositional choices in this corpus:

49. A strong elected prime minister is important for the UK (N1d, political analysis) 50. There are interesting linguistic techniques used in order to create humour (UK3, linguistic investigation)

By considering sub-categories of hedges, boosters and engagement markers, these results imply that each genre is characterised by a particular palettes of interactional resources, such as the use of rounders in political analyses to draw on statistics and a combination of boosters and engagement markers in the opinion pieces to convince readers of the author's arguments.

\section{Discussion}

The results of this exploratory study indicate that in analysing less prestigious genres (Ädel, 2018), researchers may benefit from drawing on a broad range of metadiscourse categories from previous studies of other geners in order to address more sensitively the corpus in question (e.g. Ho \& Li, 2018). By adapting a taxonomy to the content of the corpus, this analysis provides insight into the kinds of metadiscoursal resources that pupils relied on in five genres written at British and Norwegian upper secondary schools. As mentioned, this study does not aim to compare essays written by first and second language speakers. Instead, the aim is to investigate the types of metadiscourse on which pupils at this level rely and the effect that the target genre may have on their compositional choices.

Regarding signposting, it seems that the frequencies of transitions (Dobbs, 2013) and exemplifiers (Cao \& Hu, 2014) resemble those found in other corpora. This suggests there is a general need in knowledge-based writing to signal relations of addition, comparison and inference. There also seems to be a common reliance on exemplification, in this case to specify meaning, prove knowledge and support argumentation.

Phoric markers and topic markers were relatively infrequent overall, perhaps due to the short length of the majority of the texts in the corpus. In writing short texts, pupils tended not to enumerate arguments, refer to other parts of the text or the text itself, or mark introductions and conclusions. The linguistic investigations diverge from this trend, perhaps because these were the longest texts, were divided into sub-sections, and were the most academic-like genre (Hempel \& Degand, 2007). Furthermore, compared with other essays, essay UK24 contained more enumerators and essay UK8 contained more pre- and review markers, indicating that the use of such markers may represent individual styles.

Regarding stance, the present results support suggestions (e.g. Qin \& Uccelli, 2019) to use sub-categories of hedges to investigate the genre-dependent ways in which upper secondary pupils mitigate and strengthen their claims. For example, 
rounders were used in political analyses to make generalisations and to discuss statistics, while downtoners and first-person hedges were used in the reflective pieces to informally and tentatively discuss the authors' creative abilities. Regarding boosters, the amplifier and plausibility booster sub-categories were most frequent in the opinion pieces, illustrating the more rhetorical orientation of this genre.

The findings regarding hedges and boosters are comparable to other studies of novice writing (e.g. Dobbs, 2014; Hinkel, 2005) in that these argumentative features were used at relatively similar frequencies in the corpus. In professional genres, hedges are used up to four times more frequently than boosters (e.g. Dafouz-Milne, 2008; Fu \& Hyland, 2014; Hu \& Cao, 2011). Additionally, Lee and Deakin (2016) find that higher frequencies of hedges are equated with higher quality writing, and Hinkel (2005) equates boosting with more informal discourse. While it seems that tentativeness is valued in professional English writing, the essays in this corpus were comparatively over-confident, exemplified by the use of universal boosters, which were relatively frequent in all five genres. These findings therefore suggest that upper secondary pupils may benefit from explicit guidance in making knowledge claims (e.g. Qin \& Uccelli, 2019).

The frequent use of engagement markers and boosters in the opinion pieces highlights the more argumentative nature of this genre. Similarly, Fu and Hyland (2014, p. 24-25) found that professionally written opinion pieces use boosters to "offer strong support for arguments" and engagement markers to "establish proximity with readers" and to "draw readers into [the] argument". The use of reader references in the literary analyses offers support for Afros and Schryer (2009), who found that literary scholars more frequently use inclusive-we in drawing conclusions. However, reader pronouns in these literary analyses were mostly used in assuming that the audience had already read the texts in question. Although the political analyses and linguistic investigations also had argumentative purposes, directly engaging readers and confidently presenting arguments were less prominent features of these genres.

Similar to previous research (e.g. Cao \& Hu, 2014), evidentials were frequently used in this corpus, mostly to discuss the material that the pupils aimed to analyse, or to draw on other sources to support arguments. This indicates that these pupils recognised the rhetorical importance of providing evidence for their claims. Furthermore, the higher frequencies of evidentials in the linguistic investigations and in the opinion pieces suggest that the pupils writing under process-oriented conditions were able to use a wider range of relevant sources, but a larger corpus would be needed to confirm this. Notably, evidentials were least frequent in the reflective pieces, serving a specific purpose when they were used: to draw on advice that the authors had received from friends and teachers, which may be perceived as being overly personal in other genres. Furthermore, the corpus contained a number of evidentials, such as "portray" and "uses", that have not been reported in other studies (e.g. Hyland, 2019). This might suggest that pupils use a wider range of markers to refer to text external sources than would be expected in professional writing. 


\section{F. F. Thomson}

Previous studies have found that self-mentions serve several purposes in professional writing (Harwood, 2005; Fu \& Hyland, 2014). While self-mentions were present in 32 of 35 of the British school essays, they were present in only five of the 21 Norwegian school essays. This means that pupils at the Norwegian schools tended not to use self-mentions as would be expected in professional writing. This contrasts with Ädel (2006), who found Swedish students frequently used self-mentions. Since the absence of self-mentions in the Norwegian school essays cannot be explained by genre or by the pupils' status as second language learners, it may be that their teachers promoted a more traditional view of scientific writing: "that it simply reflects indisputable 'facts' which have been proved by replicable empirical investigation" (Harwood, 2005, p. 1208). Considering research that shows self-mentions are being more frequently used in modern academic writing (Hyland \& Jiang, 2016), this study tentatively offers support for Crismore, Markkanen and Steffenssen (1993, p. 68) who argue that "teachers must dispel the folklore and myths about what some teachers and textbooks say that writers do".

Attitude markers were more frequent in the rhetorically oriented opinion pieces, but these markers were nonetheless relatively infrequent in all genres. Similar to previous studies (e.g. Hyland, 2012), the most frequent attitude markers in this corpus were "important" and "interesting". However, the search terms used for this study were largely based on those used for investigations of academic writing (Hyland, 2019). A broader range of search terms, based on Martin's (1999) appraisal framework for example, could be used to reveal more about how upper secondary pupils express their attitudes.

\section{Conclusion}

By drawing on sub-categories from a range of previous studies based on the content of the current corpus, this study was able to capture sensitively the metadiscourse markers upon which this sample of upper secondary pupils at Norwegian and British schools relied. The findings reveal the metadiscoursal characteristics in each of the five genres. For example, in the opinion pieces, pupils used higher frequencies of reformulators as they strived both to impress examiners and to engage lay readers, balancing jargon with everyday vocabulary. In the political analyses, rounders accompanied arguments supported by statistics and broad generalisations. Compared to previous studies, it was evident that the frequencies of certain metadiscoursal features conformed to professional writing practices, while others did not. On the one hand, the overall use of transitions, code glosses and evidentials supports the hypothesis that knowledge-based writing relies on textual cohesion and on supporting claims with evidence (e.g. Cao \& $\mathrm{Hu}, 2014)$. On the other, while professional writing is often typified by higher frequencies of hedges (e.g. Hu \& Cao, 2015), the present corpus contained similar frequencies of hedges and boosters, and the use of universal boosters in particular suggests pupils presented their arguments with an inappropriate level of confidence. 
This study faces several limitations that prevent drawing firmer conclusions. For example, inductive statistical tests could not be conducted due to the size of the sample, which was collected from a small number of pupils, whose personal writing styles may be overrepresented in the present material. Furthermore, although the data represents the genres in which pupils usually write, comparing essays written for various prompts under either timed or process-oriented conditions remains problematic (e.g. Ädel 2008) and a number of other variables, such as the individual proficiency of each pupil, may account for the findings reported here.

The findings suggest that pupils at this level are able to adapt their use of metadiscourse to the target genre, such as pupil UK4 who differentiated their use of boosters and engagement markers in their linguistic investigation and opinion piece. In order to substantiate these findings, future research could use a larger corpus to investigate how pupils respond to different genres. Furthermore, individual teacher advice may have affected pupils' metadiscoursal choices, which also warrants further investigation (e.g. Hong \& Cao, 2014).

Although the taxonomy used here still does not capture all the potential sub-categories that may be present in upper secondary writing, such as sub-categories of attitude markers, the results illustrate how future research that aims to analyse less prestigious genres (Ädel, 2018) may produce more nuanced results by consolidating sub-categories from various previous studies to address the features of the corpus in question.

\section{Author biography}

James Jacob Thomson is a Ph.D. fellow at the University of Stavanger. Based on his previous experience working as an English teacher, he became interested in various features of English essay writing. His current research thus aims to contribute to understanding pre-tertiary writing practices at Scandinavian and British upper secondary schools.

\section{Acknowledgements}

My gratitude goes to Ion Drew, Oliver Traxel, Maria Kuteeva, Milica Savic and Liviana Galiano for their invaluable contributions to this paper, and to all the pupils and teachers for cooperating with me on this project. I would also like to thank the anonymous reviewers for their detailed and constructive input.

\section{Funding body}

University of Stavanger

\section{References}

Abdi, R., \& Ahmadi, P. (2015). Signposting propositions: A study of interactive metadiscourse marking in the composition of research articles across sciences. Fournal of Research in Applied Linguistics 5, 5-17. 


\section{F. Thomson}

Abdi, R., Rizi, M. T., \& Tavakoli, M. (2010). The cooperative principle in discourse communities and genres: A framework for the use of metadiscourse. Fournal of Pragmatics 42, 1669-1679.

Afros, E., \& Schryer, C. F. (2009). Promotional (meta)discourse in research articles in language and literary studies. English for Specific Purposes 28, 58-68.

AQA Education (AQA). (2019). AS and A-level English Language. Manchester: AQA. Retrieved from (30.10.2019): https://filestore.aqa.org.uk/resources/english/specifications/AQA-7701-7702-SP-2015.PDF.

Blagojevic, S. (2004). Metadiscourse in academic prose: A contrastive study of academic articles written in English by English and Norwegian native speakers. Studies about Languages 5, 60-67.

Brezina, V., McEnery, T., \& Wattam, S. (2015). Collocations in context: A new perspective on collocation networks. International fournal of Corpus Linguistics 20, 139-173.

Çandarli, D., Bayyurt, Y., \& Mart1, L. (2015). Authorial presence in L1 and L2 novice academic writing and cross-cultural perspectives. Fournal of English for Academic Purposes 20, 192-202.

Cao, F., \& Hu, G. (2014). Interactive metadiscourse in research articles: A comparative study of paradigmatic and disciplinary influences. Fournal of Pragmatics 66, 15-31.

Council of Europe. (2001). Common European framework of reference for languages: Learning, teaching, assessment. Cambridge: University of Cambridge.

Crismore, A., Markkanen, R., \& Steffensen, M. (1993). Metadiscourse in persuasive writing: A study of texts written by American and Finnish university students. Written Communication 10(1), 39-71.

Dafouz-Milne, E. (2008). The pragmatic role of textual and interpersonal metadiscourse markers in the construction and attainment of persuasion: a cross-linguistic study of newspaper discourse. Fournal of Pragmatics 40, 95-113.

Dahl, T. (2004). Textual metadiscourse in research articles: a marker of national culture or of academic discipline?. Fournal of Pragmatics 36, 1807-1825.

Dobbs, C. L. (2013). Signaling organization and stance: academic language use in middle grade persuasive writing. Reading and Writing 27, 1327-1352.

Education First. (2019). EF English Proficiency Index. Retrieved from (30.10.2019): https://www.ef.no/epi/.

$\mathrm{Fu}, \mathrm{X} .$, \& Hyland, K. (2014). Interaction in two journalistic genres: a study of interactional metadiscourse. English Text Construction 7, 122-144.

Halliday, M. A. K., \& Matthiessen, C. M. I. M. (2014). An Introduction to Functional Grammar (Fourth Edition). London: Routledge.

Harwood, N. (2005). 'Nowhere has anyone attempted ... In this article I aim to do just that'A corpus-based study of self-promotional $I$ and we in academic writing across four disciplines. Fournal of Pragmatics 37, 1207-1231.

Hasselgård, H. (2016). Discourse-organizing metadiscourse in novice academic English. In M. J. López-Couso, B. Méndez-Naya, P. Núñez-Pertejo and I. M. Palacios-Martínez (eds.), Corpus linguistics on the move: Exploring and understanding English through corpora (p. 106-131). Leiden: Brill Rodopi.

Hempel, S., \& Degand, L. (2008). Sequencers in different text genres: Academic writing, journalese and fiction. fournal of Pragmatics 40, 676-693.

Hinds, J. (2011). Reader versus writer responsibility: A new typology. In T. Silva \& P. K. Matsuda (eds.). Landmark Essays on ESL Writing. London: Routledge. 63-74.

Hinkel, E. (2005). Hedging, Inflating, and Persuading in L2 Academic Writing. Applied Linguistic Learning 15, 29-53.

Ho, V., \& Li, C. (2018). The use of metadiscourse and persuasion: An analysis of first year university students' timed argumentative essays. Fournal of English for Academic Purposes 33, 53-68.

Hong, H., \& Cao, F. (2014). Interactional metadiscourse in young EFL learning writing. International fournal of Corpus Linguistics 19(2), 201-224.

Hu, G., \& Cao, F. (2011). Hedging and boosting in abstracts of applied linguistics articles: A comparative study of English- and Chinese-medium journals. Fournal of Pragmatics 43, 2795-2809.

Hu, G., \& Cao, F. (2015). Disciplinary and paradigmatic influences on interactional metadiscourse in research articles. English for Specific Purposes 39, 12-25.

Hyland, K. (2005). Stance and engagement: a model of interaction in academic discourse. Discourse Studies 7 , 173-192.

Hyland, K. (2007). Applying a gloss: exemplifying and reformulating in academic disciplines. Applied Linguistics $28,266-285$.

Hyland, K. (2012). Undergraduate understandings: Stance and voice in final year reports. In K. Hyland \& C. Sancho-Guinda (eds.), Stance and Vice in Written Academic Genres (p. 134-150). Basingstoke: Palgrave Macmillan. 


\section{Metadiscourse in upper secondary pupil essays}

Hyland, K. (2017). Metadiscourse: What is it and where is it going?. Fournal of Pragmatics 113, 16-29.

Hyland, K. (2019). Metadiscourse: Exploring Interaction in Writing. London: Continuum.

Hyland, K., \& Jiang, F. (2018). 'In this paper we suggest': Changing patterns of disciplinary metadiscourse. English for Specific Purposes 51, 18-30.

Lee, J. J., \& Deakin, L. (2016). Interactions in L1 and L2 undergraduate student writing: Interactional metadiscourse in successful and less-successful argumentative essays. Fournal of Second Language Writing 33, 21-34.

Lowie, W. \& Seton, B. (2013). Essential Statistics for Applied Linguistics. Basingstoke: Palgrave Macmillan.

Mackey, A., \& Gass, S. M. (2016). Second Language Research: Methodology and Design. London: Routledge.

Martin, J. R. \& White, P. (2005). The Language of Evaluation: Appraisal in English. Basingstoke: Palgrave Macmillan.

Paltridge, B. (1995). Working with genre: A pragmatic perspective. Fournal of Pragmatics 24, $393-406$.

Prince, E. F., Frader, J., \& Bosk, C. (1980). On Hedging in Physician-Physician Discourse. Presented at the AAAL Symposium on Applied Linguistics in Medicine. University of Pennsylvania.

Qin, W. \& Ucceli, P. (2019). Metadiscourse:Variation across communicative contexts. Fournal of Pragmatics 139, 22-39.

Salager-Meyer, F. (1994). Hedges and Textual Communicative Function in Medical English Written Discourse. English for Specific Purposes 13, 149-170.

Uccelli, P., Dobbs, C., \& Scott, J. (2013). Mastering academic language: Organization and stance in the persuasive writing of high school students. Written Communication 30, 36-62.

Utdanningsdirektoratet (Udir.). (2013). Lereplan i Engelsk. Oslo: Utdanningdirektoratet. Retieved from (30.10. 2019): https://www.udir.no/laring-og-trivsel/lareplanverket/finn-lareplan/lareplan/?kode=ENG1-03.

Vande Kopple, W. J. (1985). Some exploratory discourse on metadiscourse. College Composition and Communication 36, 82-93.

Ädel, A. (2006). Metadiscourse in L1 and L2 English. Amsterdam: John Benjamins Publishing Company.

Ädel, A. (2008). Metadiscourse across three varieties of English. In U. Conner, E. Nagelhout, \& W. V. Rozycki, (eds.), Contrastive Rhetoric: Reaching to Intercultural Rhetoric (p. 45-62). Amsterdam: John Benjamins.

Ädel, A. (2010). Just to give you a kind of map of where we are going: a taxonomy of metadiscourse in spoken and written academic speech. Nordic fournal of English Studies 9, 69-97.

Ädel, A. (2018). Remember that your reader cannot read your mind: Problem/solution-oriented metadiscourse in teacher feedback on student writing. English for Specific Purposes 45, 54-68. 


\section{f. F. Thomson}

\section{Appendix: Search terms}

Attitude markers (36): agree, appropriate, correctly, curious, disappointed, disappointing, dramatic, dramatically, essentially, expected, honest, honestly, hopefully, important, importantly, inappropriate, inappropriately, interesting, interestingly, naturally, prefer, preferred, shocking, shockingly, significant, surprised, surprising, surprisingly, unbelievable, understandable, unexpected, unfortunate, unfortunately, unusual, usual, !

\section{Boosters}

Amplifier (32): alone, and, big, especially, even, extreme, extremely, far, greatly, highly, huge, impossibly, indeed, just, major, much, only, particularly, perfect, perfectly, pure, purely, really, severely, significantly, so, such, super, terribly, utterly, very, yet

Plausibility (26): actually, apparent, certain, certainly, clear, clearly, definitely, direct, directly, fact, knew, know, must, obvious, obviously, of course, real, reality, really, show, showed, showing, shows, supports, true, truly

Universal (38): all, always, any, anybody, anyone, anything, biggest, closest, complete, completely, easiest, entire, entirely, every, everyone, exact, exactly, farthest, forever, funniest, greatest, highest, impossible, most, never, newest, nicest, no one, nobody, none, nothing, only, sole, strongest, subtlest, throughout, totally, whole

\section{Code glosses}

Exemplifier (18): as, can be seen, e.g., example, examples, highlighted, include, included, includes, including, instance, illustrates, illustration, like, say, shown, such,) Reformulator (6): in other words, meaning, means, meant, otherwise,)

\section{Engagement Markers}

Question (1): ?

Reader reference (15): let's, our, reader, readers, us, we, we're, we've, you, you'd, you'll, your, you're, you've, yourself

Directive (5): compare, consider, look, remember, think

Evidentials (93): according, addressed, addresses, argue, argues, believe, believed, believes, claim, claimed, claiming, claims, conveyed, criticize, criticized, criticizing, deals, depict, depicted, depicts, describe, described, describes, describing, description, discuss, discusses, employ, employs, estimated, explained, explains, explanation, feel, feeling, felt, include, included, includes, judge, judged, mentioned, mentions, opinion, outline, outlines, portrayed, portrays, proposal, propose, proposed, refer, referred, refers, repeated, repeating, repeats, replied, replies, reply, replying, said, say, 
says, saw, sees, show, showed, shows, state, stated, suggest, suggested, suggesting, suggests, supports, talk, talked, talks, tell, tells, think, thought, told, use, used, uses, using, write, writes, written, wrote,)

\section{Hedges}

Rounders (48): almost, around, bit, certain, common, commonly, fair, few, fewer, frequent, frequently, general, generally, great, hundreds, largely, little, lot, lots, majority, many, most, mostly, much, multiple, normally, number, numerous, often, or so, other, others, range, regular, regularly, roughly, several, some, sometimes, tend, tends, thousands, towards, usual, usually, variety, various, widely

Downtoners (26): almost, as, barely, bit, borderline, certain, essentially, fairly, hardly, in a way, just, kind, little, only, practically, pretty, quite, rather, relatively, simply, slight, slightly, some, somewhat, sort of, -ish

Plausibility shield (44): apparent, apparently, appear, appeared, appears, arguably, assume, can, could, evidence, implied, implies, imply, implying, indicate, indicated, indicates, indicating, indication, likely, may, maybe, might, necessarily, perhaps, possibility, possible, possibly, potential, potentially, probably, propose, seem, seemingly, seems, suggest, suggested, suggesting, suggestion, suggests, support, supported, supporting, supports

First Person Hedge (6): believe, believed, guess, opinion, think, thought

\section{Phoric markers}

Enumerator (12): final, finally, first, firstly, following, followed, last, lastly, next, second, secondly, third

Pre- and review (9): again, as I said, established, mentioned, former, last, latter, stated, will

Self mention (9): I, I'd, I'll, I'm, I've, me, my, myself, we

\section{Topic markers}

Introducing (8): essay, intend, introduction, investigate, investigation, paper, task, text Reference to text (3): project, study, investigation

Concluding (5): conclude, conclusion, final, last, overall

\section{Transitions}

Additive (13): addition, additionally, along with, alongside, also, another, as, at the same time, further, furthermore, moreover, otherwise, too 


\section{F. F. Thomson}

Comparative (37): all the same, although, as, aside, but, comparison, contrast, contrastingly, conversely, correspondingly, despite, equally, even if, even though, however, instead, like, moreover, nevertheless, no matter, nonetheless, on the other hand, oppose, opposed, or, otherwise, nor, rather, regardless, similarly, still, than, though, whereas, while, whilst, yet

Inferential (36): as, based on, because, cause, caused, causes, consequently, due, following, given that, hence, if, in order to, in this way, lead, leading, leads, mean, meaning, means, meant, otherwise, outcome, reason, result, resulting, results, since, so, thereby, then, therefore, thus, unless, when, with this in mind

526 search terms in total 